The University of Southern Mississippi

The Aquila Digital Community

Faculty Publications

3-1-2013

\title{
An Exploratory Study of Adult Amateur Musicians' Identification of Instrumental Timbre
}

Amanda L. Schlegel

University of Southern Mississippi, Amanda.Schlegel@usm.edu

Jeremy S. Lane

University South Carolina

Follow this and additional works at: https://aquila.usm.edu/fac_pubs

Part of the Music Commons

\section{Recommended Citation}

Schlegel, A. L., Lane, J. S. (2013). An Exploratory Study of Adult Amateur Musicians' Identification of Instrumental Timbre. Bulletin of the Council for Research in Music Education(196), 65-79.

Available at: https://aquila.usm.edu/fac_pubs/7838

This Article is brought to you for free and open access by The Aquila Digital Community. It has been accepted for inclusion in Faculty Publications by an authorized administrator of The Aquila Digital Community. For more information, please contact Joshua.Cromwell@usm.edu. 
RUNNING HEAD: Descriptive Analysis of Published Qualitative Research

\section{A Descriptive Analysis of Qualitative Research Published in}

Two Eminent Music Education Research Journals

Dr. Jeremy S. Lane

School of Music, University of South Carolina

Submitted to the Bulletin of the Council for Research in Music Education

October 26, 2009 


\section{A Descriptive Analysis of Qualitative Research Published in}

Two Eminent Music Education Research Journals

\section{$\underline{\text { Introduction }}$}

The use of qualitative methods in systematic research has increased dramatically in the past decades (Bogdan \& Biklin, 2007; Patton, 2002). From origins in the social sciences during the 1960's, the body of qualitative research has expanded to include countless articles, books, papers, and monographs across all manner of academic fields. This growth can be in part attributed to the nature of inclusion within qualitative inquiry; as one author noted, "Qualitative method assumes everyone has a story to tell." (Bogdan \& Biklin, p. xiii).

Qualitative contributions to music education research have also increased. A content analysis of publications in the Journal of Research in Music Education (Yarbrough, 2002) indicated an increase in qualitative studies published from 19842002. Other journals such as the Bulletin of the Council for Research in Music Education, the Journal of Music Therapy, and Update: Applications of Research in Music Education have contributed to qualitative research in music education through publications of papers presented at symposiums as well as peer-reviewed articles. Handbooks specific to music education in research design and methods (Bresler \& Stake, 2006) have also provided overviews of qualitative procedures and techniques.

The increase in qualitative approaches has solidified the value of naturalistic inquiry; however, this increase has also raised questions about the appropriateness, 
validity, and uses of specific terms and research types. Patton (2002) describes the dilemma as follows:

With less need to establish the value of qualitative inquiry by debating those of quantitative and experimental persuasion, qualitative inquirers have turned their attention to each other, noticing that they are engaging in different kinds of qualitative inquiry from widely different perspectives. (p. xxii)

Bennett Reimer (2006) wrote that “...[W]hat music education research becomes in the next couple of decades depends on how the music education research community digests what has occurred and is occurring in the larger field of research and responds in considered, complementary ways" (p. 25). In a similar vein, Conway (2003) asserts the need for examination and review of research methods used in our profession. Through such examination, music educators may gain a better perspective on a) the usage and role of qualitative inquiry in music, and b) how research in our field relates to the broader scope of qualitative research in general.

It seems, then, that a logical place to begin inquiry into the nature of qualitative research in music education would be through review and analysis of extant literature. This approach has been used many times for a variety of purposes, including assessments of researcher eminence and productivity (Britten \& Standley, 1997; Kratus, 1993; Standley 1984), assessments of journal eminence (Hamann \& Lucas, 1998), descriptors of scholarly quality of articles (LeBlanc \& McCrary, 1991) and content analyses of journal articles (Schmidt \& Zdinski, 1993; Yarbrough, 2002; Yarbrough, 1984). Other researchers have examined the makeup of editorial 
committees (Humphreys \& Stauffer, 2000) and characteristics of samples used in quantitative research (Ebie, 2002).

The primary goal of this study is to provide an overview of qualitative research being published in each of these journals, including the names of authors and frequencies of their publications, and the types of methods used most frequently. Also included in this review is the identification of what I have labeled foundational sources. By this I mean sources that are generally included in the reference lists of a qualitative study primarily and serve to establish definitions of key terms and guidelines for procedures of data collection, analysis, reliability, or other aspects of research design. I have chosen to limit foundational sources to books only, as books seem more likely to serve the purpose of reference for research design (as opposed to short-form articles). Given that the modes of qualitative research originated in fields outside music (such as general education and the social sciences), I reasoned that the majority of foundational sources that would inform practice in our field would not (at this point in time) be specific to music research. By identifying which sources are most common in our field, we can gain better perspective as to the origination and usage of nomenclature in published music education research literature, and better understand relationships among common practice in music research and qualitative research in other fields.

In summary, the purpose of this study was to examine the extant literature of qualitative research published in two eminent music education journals. The project was guided by the following research questions: 
1) What is the representation of qualitative reports among the overall literature published in these journals?;

2) What are the most common research methods and techniques?;

3) Who are the authors who have published qualitative research in these journals? and

4) What are the most commonly cited foundational sources?

\section{Method}

\section{Selection of Journals}

For this study, I used articles published in the Journal of Research in Music Education (JRME) and the Bulletin of the Council for Research in Music Education (CRME) between 1983 and 2008. I selected these journals because they have been identified as the two most eminent music education research journals published in the United States (Hamman \& Lucas, 1998; Kratus, 1993). I selected the date range of 1983-2008 for two reasons: 1) Yarbrough's content analyses of JRME (2002) indicated that there were no qualitative studies published in that journal prior to 1983, and 2) it provided a 25-year window of extant research for review.

\section{Selection of Studies for Review}

To identify qualitative studies in each of these journals, I examined hard copies of every issue of each journal published within the 25-year range. For JRME, the range began with Volume 31, Number 1 (Spring 1983) and ended with Volume 56, Number 3 (October 2008) ${ }^{1}$. For CRME, the range began with Number 75 (Winter

\footnotetext{
1 The system for numbering issues of JRME changed after Volume 56, No. 1. Prior to this, each volume had four issues: Spring (issue number 1), Summer (number 2), Fall (number 3) and Winter (number 4). Beginning with Volume 56, No. 2, the seasonal title was removed and replaced with the month of publication.
} 
1983), and ended with Issue Number 178 (Fall 2008). In all, I examined 208 issues total; 104 issues of JRME and 104 issues of CRME.

In order to be included in this analysis, the study had be identified as a feature article or 'article of interest', either by the editor of the journal or listed as such in the table of contents; in other words, each article had to have met two specific criteria, 1) it had to have been submitted for blind review and chosen for publication by the editorial board of the publishing journal, and 2) the study had to have been identified as qualitative in nature by the authors within the text of the report. Using these criteria, I identified and reviewed a total of 65 qualitative articles. $^{2}$

Selecting articles that met the above criteria within issues of JRME was a fairly simple procedure, given that the journal follows the same basic format from issue to issue, and, with the exception of the MENC Senior Researcher award addresses, rarely publishes non-research based articles. CRME, however, publishes proceedings and papers from conferences, opinion pieces and responses, dissertation reviews, critiques, and other kinds of articles that are not usually published in JRME. For the purposes of this project, I chose not to include these other types of reports. This decision was made for two primary reasons: 1) the articles themselves were often condensed (sometimes only abstracts), and I could not ensure that the complete reference list used in the full paper was available for review, and 2) in most cases, these papers were not reviewed by the members of the CRME editorial committee.

\footnotetext{
2 Note: for the purposes of this analysis, the terms 'article', 'report', and 'study' are used interchangeably.
} 


\section{Data Collection}

Once I identified articles that fit the specified criteria, I recorded the basic information of title, author(s), and publication information (year, volume, issue, page numbers). I then read and reviewed each article to determine the type of qualitative method being employed (i.e. case study, ethnography, etc.). Finally, I reviewed the reference lists and recorded foundational sources used in developing the research design.

To collect and store data for this project, I built three separate databases/indexes using computer software applications. Apart from storing and categorizing data, these indexes aided in cross checking findings and ensuring that

results were as accurate as possible. In one index, I recorded total number of articles and the number of qualitative articles that matched my criteria, and used this information to calculate percentages of qualitative articles within each journal. In the second index, I recorded the following information for each qualitative study that met the specified criteria: author, title, number of participants, specific method used, and specific citations for foundational sources. This information was used to categorize research methods used in each study as well as to count authors and their published studies. In a third index, I recorded the specific foundational sources cited in each qualitative article and the authors of the article in which the citations were found; I used this information to calculate frequencies of citations within reviewed articles for each foundational source.

To gain additional perspectives, I conducted two post hoc searches. For the first, I searched the ProQuest Dissertations and Theses electronic database using 
author name to determine the number of articles I reviewed that were based on doctoral dissertations. I did this search only for those studies published in CRME, as JRME publishes this information with the article. For the second search, I used the cited reference search feature of the Web of Science electronic database and searched the database with the authors' names of the most cited foundational sources identified within the articles I reviewed. Results of this search provided valuable insight as to the frequency of use of these foundational sources in qualitative studies in other fields.

Once I completed the review of the selected studies and had recorded data for each article, I then used the three indexes to cross-reference and double-check findings for accuracy. Then, I revisited all hard copies of issues within the date range and went through the procedure of identifying qualitative articles a second time. Finally, I used the JSTOR and International Index of Music Periodicals (IIMP) electronic databases to search for qualitative articles published in the two selected journals during the specified date range. I set search limitations for dates and journal title, and used the keyword "qualitative" for my searches. I then compared the results of the electronic searches with the results of my hard-copy review and confirmed the identification of the studies analyzed for this project.

\section{$\underline{\text { Results }}$}

Table 1 lists the numbers of featured articles, numbers of qualitative articles, and percentages of qualitative articles in relation to total articles published for each journal in each decade and for the overall 25-year period for 1983-2008. 
Table 1: Counts of articles and percentages of qualitative articles for each journal published 1983-2008.

\begin{tabular}{cc|c|c|c|c}
\hline & & $1983-89$ & $1990-99$ & $2000-08$ & Total \\
\hline JRME & Total Articles & 137 & 275 & 199 & 611 \\
& Qualitative Studies & $3^{\mathrm{i}}$ & 5 & 20 & 28 \\
& $\%^{1}$ & $2 \%$ & $2 \%$ & $10 \%$ & $5 \%$ \\
\hline CRME & Total Articles & 146 & 97 & 152 & 395 \\
& Qualitative Studies & 0 & 2 & 35 & 37 \\
& $\%$ & $0 \%$ & $2 \%$ & $23 \%$ & $9 \%$ \\
\hline Total & Total Articles & 283 & 372 & 351 & 1006 \\
& Qualitative Studies & 3 & 7 & 55 & 65 \\
& $\%$ & $1 \%$ & $2 \%$ & $16 \%$ & $6 \%$ \\
\hline
\end{tabular}

${ }^{1}$ All percentages rounded to nearest whole number.

Overall percentages for qualitative articles for each journal seem fairly similar for the years 1983-99; since 1999, however, the percentage of qualitative articles published in CRME is slightly higher than the percentage for JRME. Both journals have published a majority of their qualitative studies within the last 10 years. The overall frequencies of articles reviewed from CRME in the years 1990-99 may at first glance seem substantially lower than the frequencies for JRME. It should be noted, though, that during these years CRME published several issues devoted to papers presented at conferences and meetings, such as the conference of the International Society of Music Education, the Symposiums for Qualitative Methodologies in Music Education Research, the Zimmerman Conference, the 
MayDay Group, the Future of Arts Education symposiums, and the Symposium for Research in General Music. Papers published in these special issues were not reviewed (see criteria described previous), which accounts for a large portion of the discrepancy between the journals for that time frame.

Table 2 lists the frequencies of single- and co-authored studies within JRME and CRME, and total frequencies of each within all reviewed studies.

Table 2: Frequencies of single- and co-authored qualitative studies.

\begin{tabular}{cccc}
\hline & JRME & CRME & Total \\
\hline Single Authored & 21 & 29 & 50 \\
Co-Authored & 7 & 8 & 15 \\
Total & 28 & 37 & 65 \\
\hline
\end{tabular}

Results indicate that a majority of published qualitative literature in music education reflects single-authorship. Co-authored studies account for less than onequarter of the body of extant literature. I identified 57 different researchers within the 65 studies I reviewed. The fifty single-authored studies represent work done by 45 different researchers, and 6 of these authors have published more than one qualitative article (single- or co-authored) in either journal. Ten of the singleauthored studies are products of doctoral dissertations (2 published in CRME; 8 in JRME). The 15 co-authored studies represent work from 22 different researchers, 18 of whom have not published any other qualitative studies (single- or -coauthored) in either journal. 
Table 3 lists contributing authors and the number of qualitative studies attributed to these authors. Colleen Conway is the most published author in the date range with 13 studies; only 11 authors have more than one publication. Forty-five authors have published qualitative research (single-, co-authored, or both) in either JRME or CRME since 2003.

Table 3: Number of qualitative publications by authors.

\begin{tabular}{cccc}
\hline Author & $\begin{array}{c}\text { Articles in } \\
\text { JRME } \\
\text { (Single/Co-authored })\end{array}$ & $\begin{array}{c}\text { Articles in } \\
\text { CRME } \\
\text { (Single/Co-authored })\end{array}$ & $\begin{array}{c}\text { Total } \\
\text { (Single/Co-authored) }\end{array}$ \\
\hline Conway, C. & $5(3 / 2)$ & $8(3 / 5)$ & $13(6 / 7)$ \\
Reynolds, A. & -- & $4(1 / 3)$ & $4(1 / 3)$ \\
Wiggins, J. & $2(2 / 0)$ & $1(1 / 0)$ & $3(3 / 0)$ \\
Kennedy, M. & $3(2 / 1)$ & -- & $3(2 / 1)$ \\
Campbell, P. & $3(0 / 3)$ & -- & $3(0 / 3)$ \\
Stauffer, S. & $1(1 / 0)$ & $1(1 / 0)$ & $2(2 / 0)$ \\
Lum, C. & $2(1 / 1)$ & -- & $2(1 / 1)$ \\
Eros, J.; Stanley, A. & -- & $2(0 / 2)$ & $2(0 / 2)$ \\
Hodgman, T. & $1(0 / 1)$ & $1(0 / 1)$ & $2(0 / 2)$ \\
Goodrich, A.; & $1(1 / 0)$ & $1(1 / 0)$ & $2(2 / 0)$ \\
12 authors & $1(1 / 0)$ & -- & $1(1 / 0)$ \\
6 authors & $1(0 / 1)$ & --- & $1(0 / 1)$ \\
22 authors & -- & $1(1 / 0)$ & $1(1 / 0)$ \\
6 authors & $--10 / 1)$ & $1(0)$ \\
\hline
\end{tabular}

Table 4 lists the frequencies of qualitative methods used in the reviewed studies. Ethnographies and case studies (both single and collective) have been the focus of more than half of the qualitative research published in JRME (17 out of 28 
Table 4: Qualitative methods used in reviewed articles.

\begin{tabular}{cccc}
\hline Method & JRME & CRME & Total \\
\hline Ethnography & 8 & 6 & 14 \\
Case Study & 6 & 6 & 12 \\
Collective Case Study & 3 & 3 & 6 \\
Grounded Theory & 3 & 3 & 6 \\
Action Research & 2 & 4 & 6 \\
Phenomenology & 1 & 5 & 6 \\
Program Evaluations & 1 & 2 & 3 \\
Other/Not specified & 4 & 8 & 12 \\
Total & 28 & 37 & 65 \\
\hline
\end{tabular}

studies) and for approximately $40 \%$ of the studies in CRME (15 out of 37). Twelve studies (out of 65 total) did not specify a particular approach, and were identified simply as qualitative in nature. Of these studies, 9 have been published within the last ten years.

Table 5 lists the foundational sources contained in the reference lists of the reviewed studies and frequencies of citations for each source. Results indicate that, in general, each study tended to include 2-3 citations for foundational sources in the descriptions of their data collection and analysis procedures. An interesting point worth noting is the high number of foundational sources published by Sage Publications; out of a total of 43 foundational sources identified in this study, approximately one-third (15) are published by Sage. 
Table 5: List of foundational sources and frequencies of citations.

Source

Denzin, N.K. \& Lincoln, Y.S. (2005). Handbook of qualitative research. Thousand Oaks, CA: Sage. ${ }^{1}$

Patton, M.Q. (2002) Qualitative research and evaluation methods. Thousand Oaks, CA: Sage. ${ }^{1}$

Seidman, I. (2006) Interviewing as qualitative research. New York: College Press. ${ }^{2}$

Bogdan, R.C. \& Biklen, S.K. (2003) Qualitative research for education: An introductory to theory and methods. Boston: Allyn \& Bacon. ${ }^{3}$

Lincoln, Y.S. \& Guba, E.G. (1985) Naturalistic inquiry. Beverly Hills: Sage.

Cresswell, J. (1998). Qualitative inquiry and research design: Choosing among the five traditions. Thousand Oaks, CA: Sage.

Miles, M.B. \& Huberman, A.M. (1994) Qualitative 6 data analysis. Thousand Oaks, CA: Sage. ${ }^{2}$

Glaser, G. \& Strauss, A. (1967). Discovery of grounded theory: Strategies for qualitative research. Chicago: Aldine.

Glesne, C. (1999). Becoming qualitative researchers. New York: Longman.

Merriam, S.B. (1998). Qualitative research and case study applications in education. San Francisco: Jossey-Bass.

Stake, R.E. (1995). The art of case study research.

Thousand Oaks, CA: Sage.

16

\footnotetext{
${ }_{1}^{1}$ Total citations across 3 separate editions (date indicates most recent edition cited).

${ }^{2}$ Total citations across 2 separate editions (date indicates most recent edition cited).

${ }^{3}$ Total citations across 4 separate editions (date indicates most recent edition cited).
} 
I used the titles of the 5 most cited foundational sources in the studies I reviewed to conduct a cited reference search of the Web of Science database, which holds information from several thousand journals in a wide array of fields. I searched 2 indexes within Web of Science (the Social Sciences Citation Index and the Arts and Humanities Citation Index), and limited the date range to citations published from 1980 to the present. Results of this search revealed approximately 400 citations for Denzin and Lincoln's Handbook of Qualitative Research, over 500 citations for both Patton's Qualitative Research and Evaluation Methods and Lincoln and Guba's Naturalistic Inquiry, and approximately 390 for Bogdan \& Biklen's Qualitative Research for Education: An Introduction to Theory and Methods. Seidman's Interviewing as Qualitative Research received the fewest hits in this search, with less than 10 citations for this book.

\section{Discussion}

Prior to the discussion of results, it should be noted that the purpose of this study was not to provide insight with regards to eminence of methods, or authors, nor establish the 'best' methods for qualitative research in music education. I conducted this study with an eye towards gaining fundamental descriptors of the state of qualitative research in our profession, and to provide some insight for future directions for research grounded in naturalistic inquiry. The results of the analysis reveal some interesting points for discussion.

In the years before 2000, qualitative research represented a small portion of the overall content published in JRME. During these years, CRME published a large amount of qualitative work, but most of these were papers from conferences and 
symposia as opposed to feature articles; the percentages of articles published in CRME prior to 2000 (that were reviewed by the CRME editorial committee) are similar to those of JRME. Since that time, however, the number of qualitative studies published in both journals has risen dramatically. This trend may reflect the overall increase in acceptance of qualitative methods within our profession, and it may reflect a simple increase in submissions of qualitative articles to these journals. Though quantitative studies represent the bulk of studies in the extant literature, it appears that research grounded in naturalistic inquiry has established itself as an important part of the extant literature in our two flagship journals.

The data suggests that there is a small body of researchers contributing to qualitative research independently and apart from their doctoral work (which is to be expected given the relative youth of naturalistic inquiry in our profession), and this body of researchers is growing steadily. As the use of qualitative methods in music education become more common, we should expect to see more contributions from a larger number of researchers.

In general, it appears that there is a small body of approximately $3-4$ foundational sources that are truly informing qualitative music education research practice. Most of these sources seem to be accepted and used in other fields as well, including the social sciences and general education. This may be helpful in one sense, as a small pool of foundational sources reflected in the literature may lend itself more easily to development of standard nomenclature, terms, and definitions. It may be detrimental, however, if the pool of foundational sources is too small and does not reflect a broad enough array of current methodological theory. 
At this point in time, music researchers have relied heavily on the ethnographic and case study approaches to qualitative research design. This seems in line with qualitative research as a whole; Merriam (2002) identifies ethnography and case study research as two of the more common, with other approaches such as grounded theory and phenomenology as less common. It is difficult to pinpoint the exact reasons why these two modes have received more attention. It may be that ethnography and case study models have characteristics that lend themselves naturally to use in music contexts, or it may be that the body of qualitative research is not yet large enough to gain a complete perspective of the effectiveness of other modes of inquiry. Additional review and analysis of various inquiry methods will be more feasible as the body of extant qualitative research literature grows. The fact that there are a notable number of studies (12 out of 65 ) that did not state a specific method of inquiry other than the basic description of being 'qualitative' is worth noting. This may be a direct result of a growing acceptance of qualitative inquiry in music research; this finding suggests that there may be a standard set of terms and procedures associated with qualitative research that are accepted enough such that identification of specific models or frameworks is not necessary.

\section{$\underline{\text { Conclusions }}$}

Based on the results of this study, it seems that future research efforts should be focused in three specific areas. First, reviews of authorship and content of qualitative research in other important journals (such as the Journal of Music Therapy and Update: Applications of Research in Music Education) can help provide more insight to the nature of qualitative research in music education. Careful 
monitoring of the authorship and publication rates of qualitative studies in these journals can help guide the developments of quality standards and accepted professional practice.

Secondly, a thorough content analysis of selected foundational sources would provide valuable insight as to the commonality (or lack of agreement) of terminology used in qualitative music research. Terms and definitions identified and described in these sources, such as triangulation, trustworthiness, and data saturation can then be compared with their use and function in music education research. Such comparisons may assist with a development of a more standard set of terms that are appropriate to qualitative research in music education

Thirdly, future research should include more detailed reviews of specific methods (such as ethnography and case studies) and the characteristics of their applications in music research. These reviews should include information related to participants, contexts, and procedures used in data collection and analysis. Findings of such reviews may be useful in developing procedures appropriate for music settings, and for generating models for use in training future professionals and graduate students in music education.

As the questions we attempt to answer grow increasingly complex, it seems imperative that our profession engages in reflective analysis and discussion. In her insightful essay, Conway (2003) states that "Music educators must continue to learn about the varying approaches to qualitative inquiry and we must continue the professional conversation regarding the appropriate use of research terminology" (p. 90). Future research efforts into the nature of qualitative research should 
promote this conversation and professional dialogue, and spur the development and growth of naturalistic inquiry in music education. 


\section{Reference List}

Bogdan, R.C. \& Biklen, S.K. (2007). Qualitative research for education: An introduction to theory and methods ( $5^{\text {th }}$ ed.). Boston: Allyn \& Bacon.

Bresler, L. \& Stake, R.E. (2006). Qualitative research methodology in music education. In Colwell, R. (Ed.), MENC Handbook of Research in Music Education (pp. 270-311). New York: Oxford University Press.

Britten, R.V. \& Standley, J. M. (1997). Researcher in music education/therapy: Analysis of publications, citations, and retrievability of work. Journal of Research in Music Education, 45 (1), 145-161.

Conway, C. (2003). Response to Edwin E. Gordon's "The Stakes Are Low But the Consequences Are High". Bulletin of the Council for Research in Music Education, No. 157 (Summer), 89-91.

Ebie, B.D. (2002). Characteristics of 50 years of research samples found in the Journal of Research in Music Education, 1953-2002. Journal of Research in Music Education, 50 (4), 280-291.

Hamann, D.L. \& Lucas, K.V. (1998). Establishing journal eminence in music education. Journal of Research in Music Education, 46 (3), 405-413.

Humprheys, J. \& Stauffer, S. (2000). An analysis of the editorial committee of the Journal of Research in Music Education, 1953-1992. Journal of Research in Music Education, 48 (1), 65-77.

Kratus, J. (1993). Eminence in music education research as measured in the Handbook of Research on Music Teaching and Learning. Bulletin of the Council for Research in Music Education, No. 118 (Fall), 21-32.

LeBlanc, A. \& McCrary, J. (1991). Acquiring criteria of excellence for scholarly journals in music. Journal of Research in Music Education, 39 (3), 206-215.

Merriam, S.B. (2002). Qualitative research in practice: Examples for discussion and analysis. San Francisco: Jossey-Bass.

Patton, M.Q. (2002). Qualitative research \& evaluation methods (3 $3^{\text {rd }}$ ed.). Thousand Oaks, CA: Sage Publications.

Reimer, B. (2006). Toward a philosophical foundation for music education research. In Colwell, R. (Ed.), MENC Handbook of Research in Music Education (pp. 337). New York: Oxford University Press. 
Schmidt, C.P. \& Zdzinski, S.F. (1993). Cited quantitative research articles in music education research journals, 1975-1990: A content analysis of selected studies. Journal of Research in Music Education, 41 (1), 5-18.

Standley, J.M. (1984). Productivity and eminence in music education research. Journal of Research in Music Education, 32 (3), 149-158.

Yarbrough, C. (2002). The first 50 years of the Journal of Research in Music Education: A content analysis. Journal of Research in Music Education, 50 (4), 276-279.

Yarbrough, C. (1984). A content analysis of the Journal of Research in Music Education, 1953-1983. Journal of Research in Music Education, 32 (4), 213-222.

\footnotetext{
$\mathrm{i}$ There is a slight discrepancy between the frequencies of qualitative studies in JRME reported in this table and those reported by Yarbrough (2002). Three studies that were included in Yarbrough's tallies were excluded from this study because they did not meet the criteria of the author identifying their study as qualitative in the text of the article.
} 